\title{
Método da eletrorresistividade para identificação de fraturas na região de Basevi, Lago Oeste - DF
}

Amanda Cecília Neuhauss Aguiar ${ }^{1}$, Welitom Rodrigues Borges ${ }^{2}$, José Eloi Guimarães Campos ${ }^{3}$, Celso Guerra Lemos ${ }^{4}$

Copyright 2019, SBGf - Sociedade Brasileira de Geofísica

This paper was prepared for presentation during the $16^{\text {th }}$ International Congress of the Brazilian Geophysical Society held in Rio de Janeiro, Brazil, 19-22 August 2019.

Contents of this paper were reviewed by the Technical Committee of the $16^{\text {th }}$ International Congress of the Brazilian Geophysical Society and do not necessarily represent any position of the SBGf, its officers or members. Electronic reproduction or storage of any part of this paper for commercial purposes without the written consen of the Brazilian Geophysical Society is prohibited.

\section{Resumo}

Este trabalho corresponde a interpretação de resultados de eletrorresistividade para auxiliar a hidrogeologia na identificação de fraturas através da correlação de anomalias geofísicas. O estudo foi realizado no Basevi, região do Lago Oeste - DF, sendo possível localizar uma fratura com potencial hídrico.

\section{Introdução}

Este trabalho teve como início uma série de estudos de eletrorresistividade financiados pela ADASA - Agência Reguladora de Àguas, Energia e Saneamento Básico do Distrito Federal, com objetivo de complementar as informações hidrogeológicas do DF, para atender uma grande demanda de perfurações de poços artesianos devido a crise hídrica que o DF têm enfrentado.

Entre os locais estudados durante a campanha, foi escolhido como área de estudo, a região do Basevi, próximo ao Lago Oeste. A escolha da área de estudo será detalhada mais adiante nesta seção.

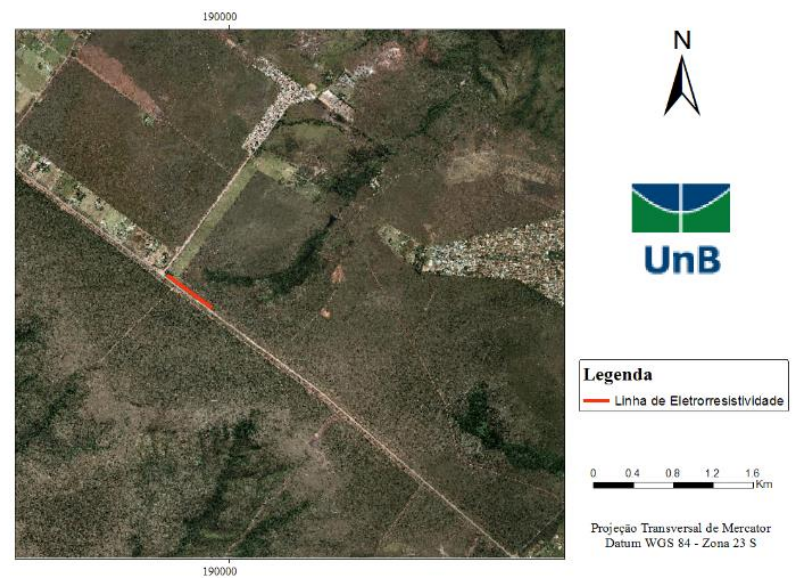

Figura 1: localização da linha de eletrorresistividade.

Dentro de um contexto regional, a área do Distrito Federal é caracterizada por rochas metamórficas recobertas por regolitos e possui 3 grupos de aquíferos, que são basicamentes caracterizados pelos domínios de água subterrânea, como o domínio intragranular, o domínio fissuro-cárstico, e o que predomina na área de estudo, o domínio fraturado (Campos, 2018).

O domínio fraturado é descrito por um meio rochoso em que o local onde percola água é caracterizado por descontinuidades, como fraturas, comum em rochas do proterozóico (Campos, 2018).

A região está localizada na unidade mesoproterozóica $Q_{3}$ do Grupo Paranoá, na formação Serra da Meia Noite, representada por fácies de quartzito médio e metarritmito arenoso. O solo da região é uma transição entre Latossolo Vermelho e Latossolo Vermelho-Amarelo. A região é predominantemente plana e possui fraturamento NE-SW (Campos, 2018).

A determinação da área de estudo, a princípio, foi feita a partir da análise de lineamentos confeccionados pela observação de feições lineares em imagens de satélite. Posteriormente, dentre todas as àreas onde havia estudos geofísicos, foi escolhida uma área para que nela fossem feitos estudos mais profundos, em que fosse possível correlacionar as anomalias geofísicas com a fratura/contato litológico identificado em um dos perfis de resistividade.

O perfil escolhido se encontra na região rural do Basevi, no lago oeste - DF (figura 1). Este perfil de resistividade foi escolhido devido a alta amostragem de pontos em subsuperfície (foram feitos 3 arranjos Dipolo-Dipolo, Wenner, Wenner-Schlumberger) e também pelo maior comprimento espacial, possuindo o maior comprimento entre os perfis da campanha.A caracterização geofísica nesse trabalho se dá pela modelagem de dados de eletrorresistividade adquiridos em três arranjos diferentes.

\section{Metodologia}

No ambiente geológico, os diferentes tipos litologías existentes, apresentam diferentes propriedades físicas, as quais refletem algumas de suas características servindo para caracterizar seus estados, em termos de alteração, fraturamento, saturação, etc., e até identificálos litologicamente, sem necessidade de escavações físicas (métodos diretos e invasivos) (Braga, 2006).

A geoelétrica abrange uma categoria de métodos que estudam as propriedades físicas relacionadas com a propagação de energia elétrica. Dentro desta categoria, encontra-se o método da eletrorresistividade, cujo princípio está baseado na determinação da resistividade elétrica dos materiais em subsuperfície, através dessas diferenças de propriedades físicas. As respostas de resistividade dependem de alguns parâmetros geológicos como a mineralogia, fluídos, porosidade e saturação de água da rocha (Loke 2004). 
MÉTOdO dA ELETRORRESISTIVIDADE NA REGIÃO DE BASEVI - DF

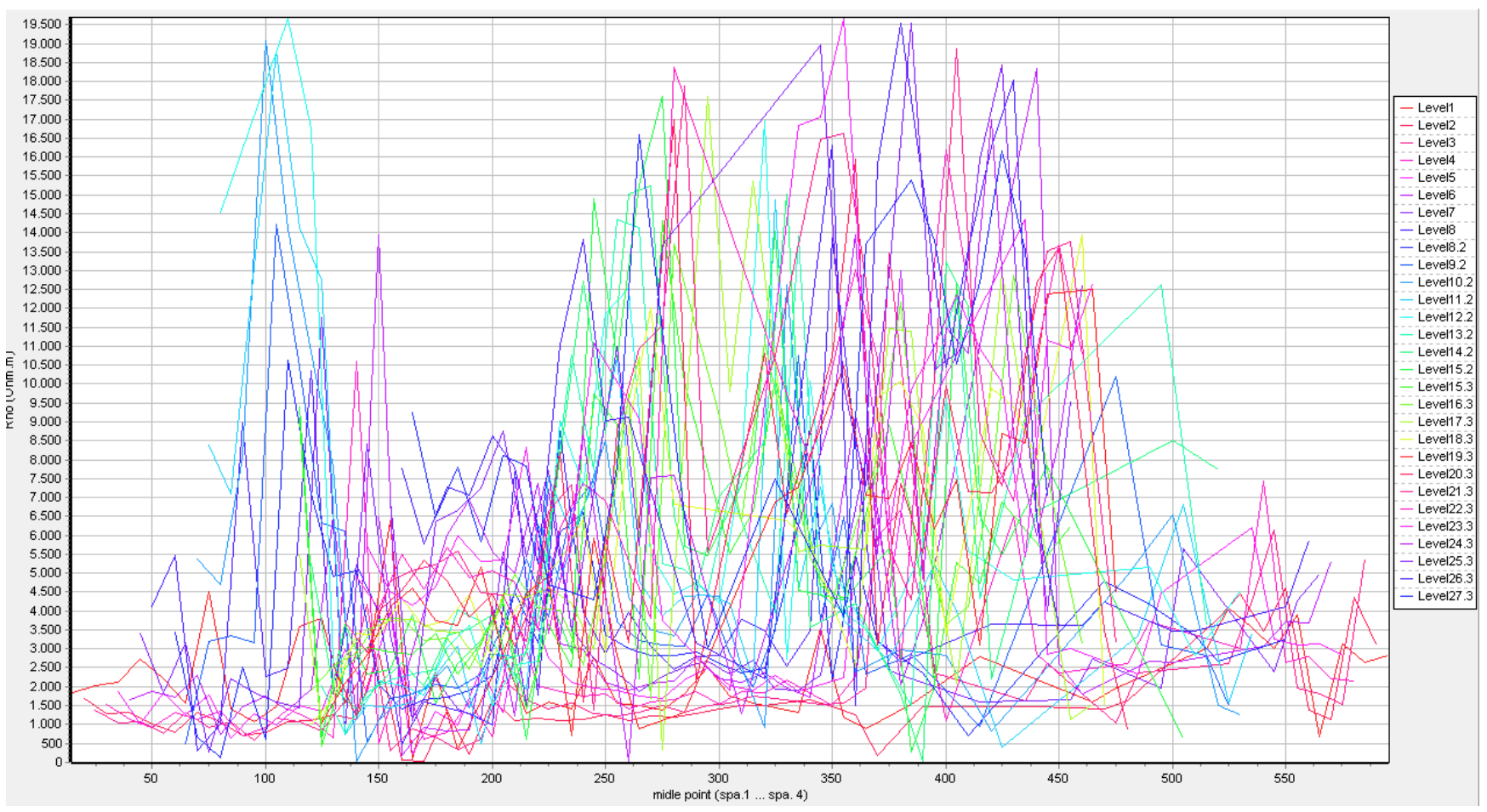

Figura 2: filtragem utilizando análise estatística.

A eletrorresistividade utiliza tanto correntes naturais da Terra, quanto correntes artificiais. As correntes artificiais são injetadas no meio através de eletrodos, visando gerar um campo potencial elétrico para determinar os valores de resistividade em subsuperfície. Durante as aquisições, normalmente, é utilizado um arranjo com 4 eletrodos, sendo um par, eletrodos de corrente, e o outro par, eletrodos de potencial. Os eletrodos de corrente injetam corrente elétrica no meio, para que fluam em subsuperfície, gerando um campo potencial. Já os eletrodos de potencial fazem as medidas do campo potencial gerado (Loke, 2004).

Os 4 eletrodos podem assumir qualquer arranjo geométrico sobre a superfície. Cada arranjo possui vantagens e desvantagens, se adequando aos objetivos de investigação do usuário. Neste trabalho foram feitas aquisições utilizando três arranjos diferentes: dipolodipolo (DD), Wenner (WN), e Wenner-Schlumberger (WS). Dessa forma, foi possível definir o melhor arranjo para este tipo de estudo, como também obtivemos um maior número de pontos investigados em subsuperfície, possibilitando fazer uma modelagem com os três arranjos em conjunto.

A aquisição foi feita utilizando o Syscal Pro, da Iris Instruments, utilizando 4 cabos, um cabo blindado de 340 metros e três cabos blindados de 90 cada um, e 62 eletrodos. O protocolo de aquisição foi feito no software Electre Pro.

A filtragem de dados espúrios foi feita no software Prosys II, da Iris Instruments, nesta etapa, a intenção é fazer uma análise estatística e retirar os valores de resistividade que não se encontram na faixa espectral de resistividade da região (figura 2 ). São retirados também os valores próximos ao zero, pois são considerados ruídos (figura 3). Neste software é possível também transformar todos os valores de resistividade em valores absolutos, para que não haja valores negativos.

A modelagem inversa dos dados de resistividade foi feita no software RES2DINV, da Geotomo, processo que consiste em transformar valores numéricos em informação visual. O tipo de inversão escolhida foi a Robusta, método mais aplicado para identificação de corpos verticais, tendo em vista que a intenção era encontrar fraturas verticalizadas com bordas de transição abrupta. No processo de inversão utilizou-se o método finite mesh grid size com 4 nós entre cada espaçamento de eletrodos, assim os valores ficam mais acurádos onde existe contraste de resistividade. Foi feita a inversão para os dados brutos e filtrados, a fim de de comparar as diferenças entre os dois resultados (figura 4).

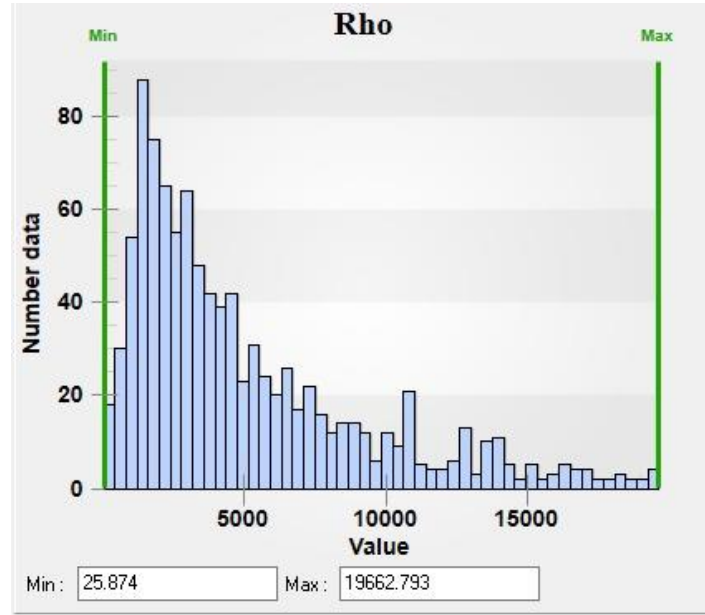

Figura 3: valores de resistividade após a filtragem. 


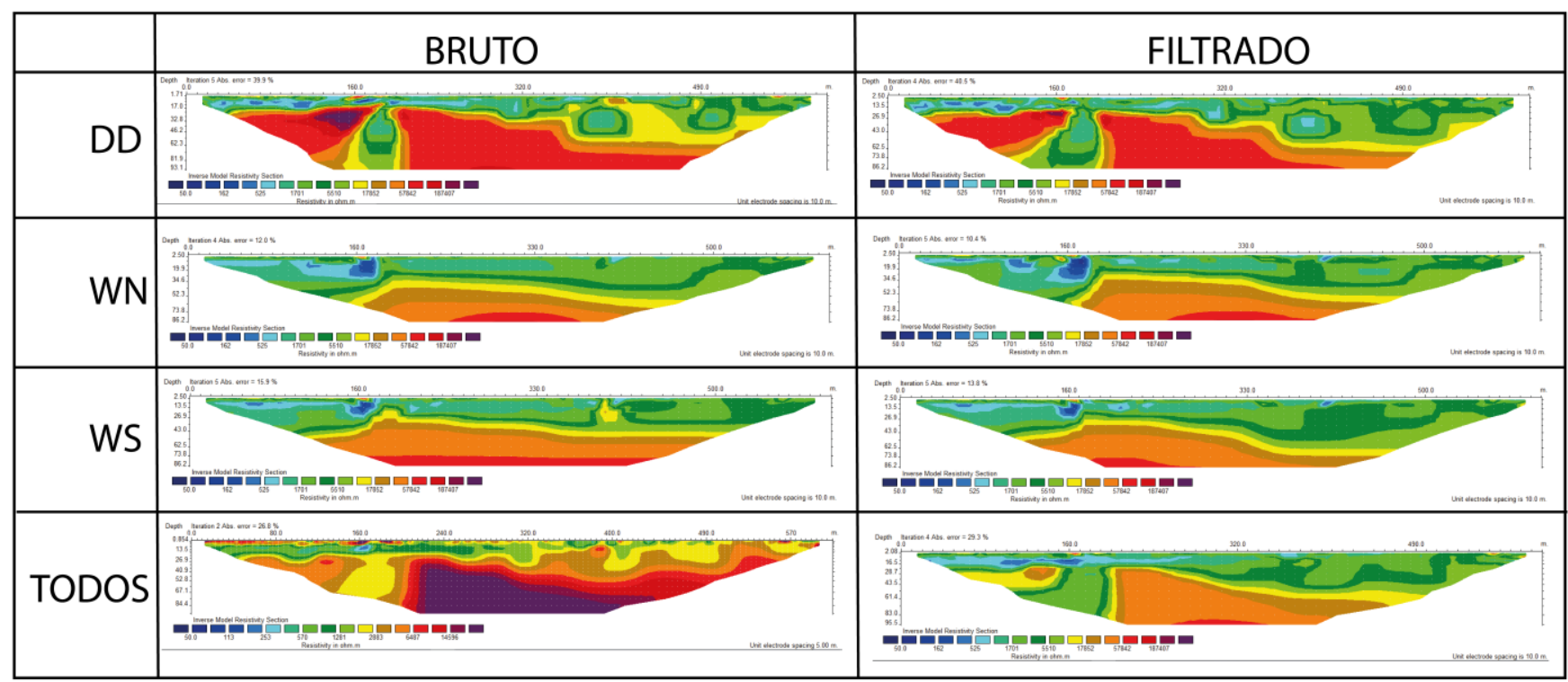

Figura 4: resultado da inversão de todos os arranjos adquiridos. (DD) Perfil Dipolo-Dipolo; (WN) Perfil Werner; (WS) Perfil Wenner-Schlumberger; (TODOS) Integração de todos os Métodos.

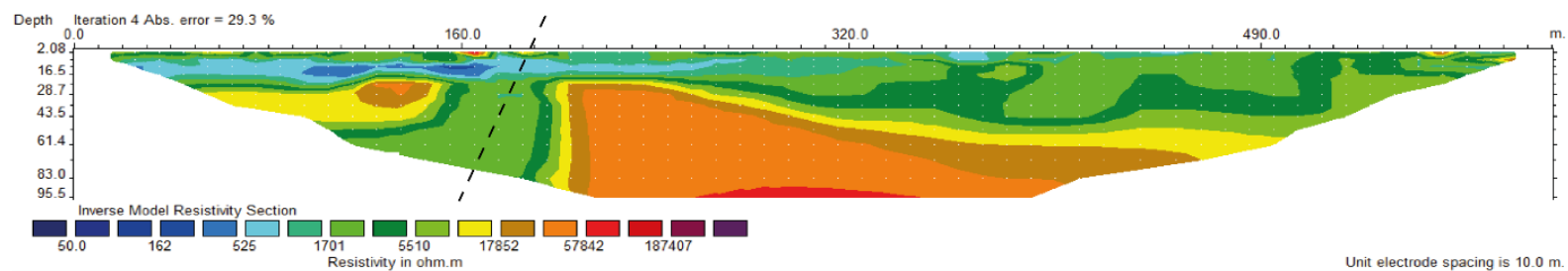

Interpretação geológica

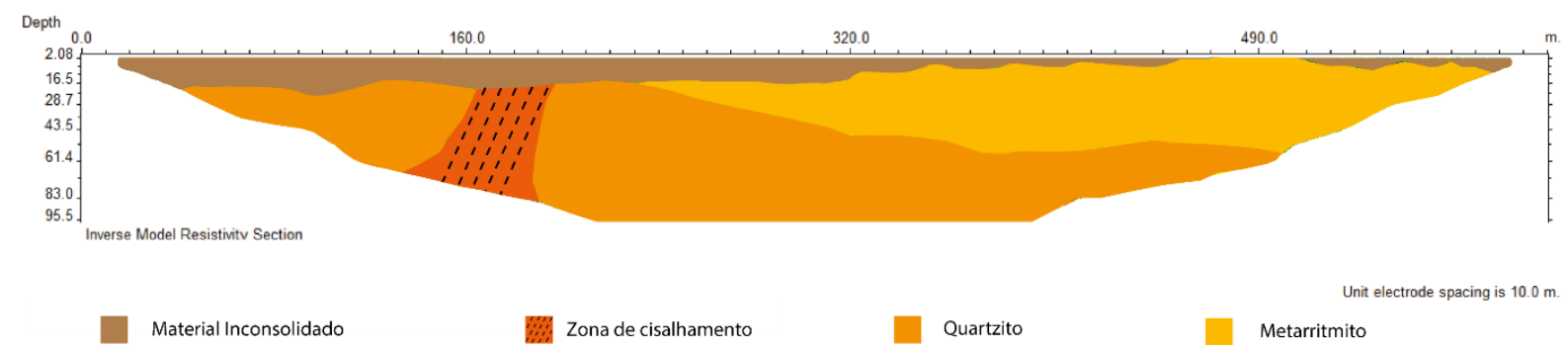

Figura 5:perfil da integração de todos os arranjos, interpretação geológica e localização da fratura.

\section{Resultados}

Os resultados da modelagem inversa dos dados de resistividades foram agrupados em forma de tabela para melhor visualização dos resultados. Analisando os perfis de resistividades de diferentes arranjos, o perfil que melhor responde a descontinuidade da fratura, como esperado, é o Dipolo-Dipolo (DD), e o perfil que melhor representa a realidade é o perfil gerado através da modelagem inversa dos dados dos três arranjos em conjunto, chamado de "todos" na figura 4.

Analisando o perfil, é possível observar algumas características principais, a fratura se encontra a 180 metros do perfil, representada pela anomalia vertical de baixa resistividade, o que significa que, provavelmente, dentro da fratura, está percolando água, deixando a região mais condutiva. O material inconsolidado possui, aproximadamente, de 10 a 16 metros de espessura, e está saturado a partir de 8 metros de profundidade, com uma abrupta variação lateral de NW para SE, onde quase não é possível observar sinal de solo. Ao saber as litologias descritas da região por Campos (2018), interpretou-se os valores de resistividade de 1701 a

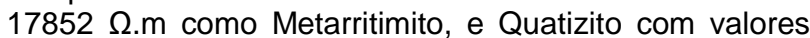
superiores a $17852 \Omega . m$ (figura 5). 


\section{Conclusões}

Através da correlação dos dados geofísicos, foi possível observar anomalias referentes à fratura, mostrando que a eletrorresistividade é eficazes na identificação de descontinuidades em subsuperfície.

Para diminuir ambiguidades e entender as respostas observadas nos perfis, é necessário correlacionar diferentes métodos geofísicos e avaliar os seus indicadores. Neste trabalho a interpretação contou com apenas dados de resistividade, outros métodos de apoio como Potencial Espontâneo e Magnetometria poderiam melhorar a compreensão da área.

O Centro-Oeste é um importante pólo de águas subterrâneas que em tempos recentes recebe pesquisas coordenadas pela Universidade de Brasília, principalmente em locais próximos do entorno do Distrito Federal. Esses projetos são uma grande oportunidade para avaliar a eficácia da geofísica como meio de investigação não invasivo de alvos submersos, por isso a abertura de estudos hidrogeológico no Basevi é muito importante para desenvolver o interesse em uma região pouco explorada.

\section{Agradecimentos}

Ao Laboratório de Geofísica Aplicada (LGA/IG/UNB) pela disponibilização dos equipamentos geofísicos, e ao Prof. Welitom Borges, pela orientação e apoio para o desenvolvimento do projeto.

\section{Referências}

LOKE M. H Electrical imaging surveys for environmental and engineering studies. A practical guide to 2-D and 3-D surveys. 2004

CAMPOS. J. E. G; SILVA. F. H. F; MOURA. C. O. Avaliação de Aquíferos Favoráveis para complementação do abastecimento de água no Distrito Federal e Locação de Poços Tuburales Profundos: Regiões Atendidas e não Atendidas pelo Sistema Integrado Descoberto - Santa Maria/Torto. Adasa. 2018

BRAGA. A. C. O. Métodos da Eletrorresistividade e Polarização Induzida Aplicados nos Estudos da Captação e Contaminação de águas Subterrâneas: uma Abordagem Metodológica e Prática. Universidade Estadual Paulista. Intituto de Geociências e Ciências Exatas. 2006 